\title{
i-Capacitor Voltage Control for PV Z-source System with Enhanced Shoot-through
}

\author{
Noor Mazliza Badrul Sham, Shamsul Aizam Zulkifli, Ronald Jackson \\ Department of Electrical Power Engineering, Faculty of Electrical and Electronic Engineering, \\ Universiti Tun Hussein Onn Malaysia (UTHM), Malaysia
}

\section{Article Info}

Article history:

Received Apr 10, 2018

Revised Sep 3, 2018

Accepted Sep 11, 2018

\section{Keyword:}

Capacitor Voltage Control (CVC)

Maximum Power Point Tracking (MPPT)

Z-source Inverter (ZSI)

Photovoltaic (PV)

Perturb and Observe (P\&O)

\begin{abstract}
This paper explains an improved capacitor voltage control (i-CVC) by combining with maximum power point tracking (MPPT) algorithm as a control strategy for a single-phase Z-source inverter (ZSI) using photovoltaic (PV) source. The existing CVC based-MPPT control algorithm has a net shoot-through interval which should be inserted in the switching waveforms of the inverter to produce maximum power at the Z-network of the PV However, this net shoot-through period is formed by an additional shootthrough period which has drawbacks as it boosts the capacitor voltage to a greater extent beyond the allowable voltage boundary of the capacitor. In other words, the PV will boost the voltage more than the desired level as per required by reference capacitor voltage of the Z-network. Due to this problem, an improved capacitor voltage control (i-CVC) with general Perturb and Observe $(\mathrm{P} \& \mathrm{O})$ based on $\Delta \mathrm{T}_{0}$ configuration of the changes shootthrough duty cycle to maintain the DC-link of the ZSI is introduced and been tested in simulation case with a resistive load. At the end, this modification able to assist the MPPT output power by increasing the overall system effectiveness of power generation by the PV.
\end{abstract}

Copyright $(\odot) 2018$ Institute of Advanced Engineering and Science. All rights reserved.

\section{Corresponding Author:}

Noor Mazliza Badrul Sham,

Department of Electrical Power Engineering,

Universiti Tun Hussein Onn Malaysia,

86400 Parit Raja, Batu Pahat, Johor, Malaysia.

Email: noormazliza@gmail.com, aizam@uthm.edu.my

\section{INTRODUCTION}

Solar power generation is one of guarantee free electrical generation today. Therefore, it has an abundant power that needs to be harvest continuously. In order to harvest this energy, a power conditioning system for PV is needed, by applying two stages converter topologies [1]. The first stage is, to boost the PV output voltage to the desired level before it can be converted to AC signal for AC source applications using the inverter at the second stage [2], [3]. This strategy requires two converters, controllers and feedback responses. As a solution, a single-stage Z-source inverter (ZSI) based on one power circuitry generation has been proposed to overcome these drawbacks appeared in the common voltage and current source inverter based on [4].

Block diagram of the improved ZSI with a unique impedance network is shown in Figure 1. As been compared in many literature studies on the ZSI, a DC-AC inversion for PV have been carried out due to their advantages such as, it used less number of components, reduce overall cost of development from harvesting the sunlight to electrical output, and enlarges its application [5], [6]. If this topology needs to be implemented in PV generation, a modification is necessary in MPPT controller in order to maintain the DC-link voltage, protect the PV module on reverse current and able to maintain the supply even after the irradiation of PV is changed without using boost converter. Some researchers have used the soft-computing technique combines with the conventional methods [7], [8] in order to have good MPPT power as well as be able to maintain the 
capacitor voltage at the Z-circuitry. However, the soft-computing approach causes the system effectiveness to be reduced and give a high cost of construction.

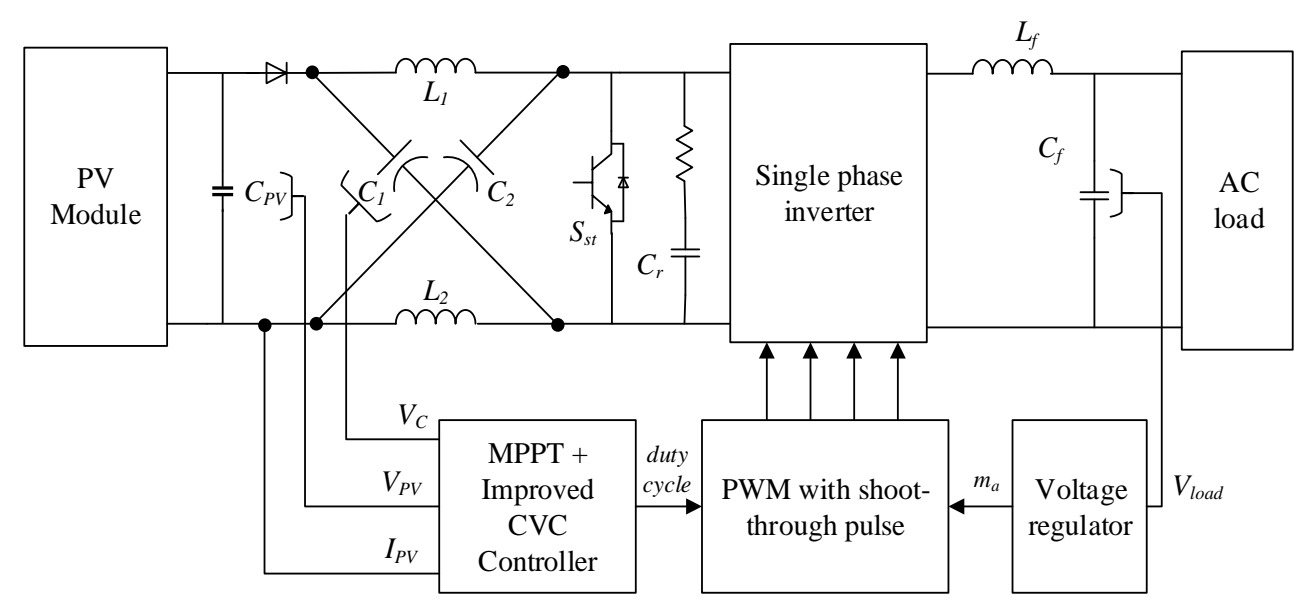

Figure 1. The proposed Control Scheme for Z-source Inverter Based PV Power Conversion System

Since all the MPPT algorithms in ZSI requires to generate a shoot-through period to extract maximum power from solar PV, this shoot through period is unable to boost the capacitor voltage at the impedance network more than the required level. Therefore, this capacitor voltage control (CVC) for ZSI is getting a lot of attention by researchers to be carried out recently. For example, a suggested controller such as traditional MPPT controller with DC-link control is needed in order to produce an additional shoot-through duty ratio and to improve the response time of MPPT controllers as have been proposed in [9], [10]. Papers [11] have proposed a unified MPPT control strategy for ZSI based on PV system to achieve MPPT as well as $\mathrm{Z}$-source capacitor voltage control at the meantime. A modified Perturb and Observe (P\&O) technique has been used for the MPPT control and the CVC as the additional controller. This modified conventional algorithms are simpler, less complex and require less parameter [12] that makes this MPPT can be implemented easily into ZSI.

There are three main factors that affect the efficiencies of a PV plant which are the inverter efficiency, MPPT efficiency and PV plant efficiency. The existing version of CVC is employed to the MPPT shoot-through interval, $\mathrm{T}_{0}$ for obtaining the total shoot-through states, $\mathrm{T}_{\mathrm{sh}}$. The $\mathrm{P} \& \mathrm{O}$ has been used as the MPPT to generate the minimum shoot-through period, $\mathrm{T}_{0}$ in order to extract maximum power point voltage from the PV module. The extra shoot-through period, $\mathrm{T}_{0}$ is generated by the capacitor voltage control (CVC) algorithm is required to increase the Z-network capacitor voltage at the PV panel. Then, the extra shootthrough period, $\mathrm{T}_{0}$ is added to the MPPT generated shoot-through interval, $\mathrm{T}_{0}$ in order to obtain the total shoot-through states, $\mathrm{T}_{\mathrm{sh}}$ as shown in Figure 2(a). However, the existing CVC algorithm, boost the capacitor voltage to a greater extent more than the allowable extra shoot-through state would withstand in which caused the capacitor voltage of Z-source cannot be constantly maintained. As a result, all the system efficiency especially, for the inverter and MPPT efficiency are been affected. Hence, this paper introduces an improved CVC (i-CVC) algorithm by adding $\mp \sum \%$ of changes $\left(\Delta \mathrm{T}_{0}{ }^{\prime}\right)$ in shoot-through duty ratio, $\mathrm{D}_{0}$ and the additional shoot-through duty ratio, $\mathrm{D}_{0}{ }^{\prime}$ in order to increase the efficiency of the whole PV system. The $\mathrm{D}_{0}$ can be denoted as $\mathrm{T}_{0} / \mathrm{T}$ and $\mathrm{D}_{0}{ }^{\prime}$ is equal to $\mathrm{T}_{0}{ }^{\prime} / \mathrm{T}$ as illustrate in Figure 2(b). Therefore, by adding $\mp \sum \%$ of $\Delta \mathrm{T}_{0}$ ' to the controller, it can reduce the drawback of the controller performance by achieve a constant capacitor voltage at input of Z-source and a maintaned DC-link voltage at the output of ZSI. 


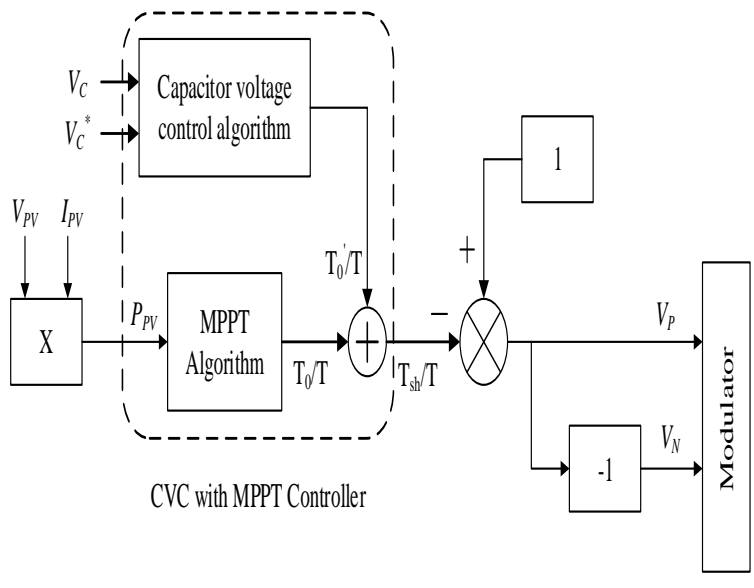

(a)

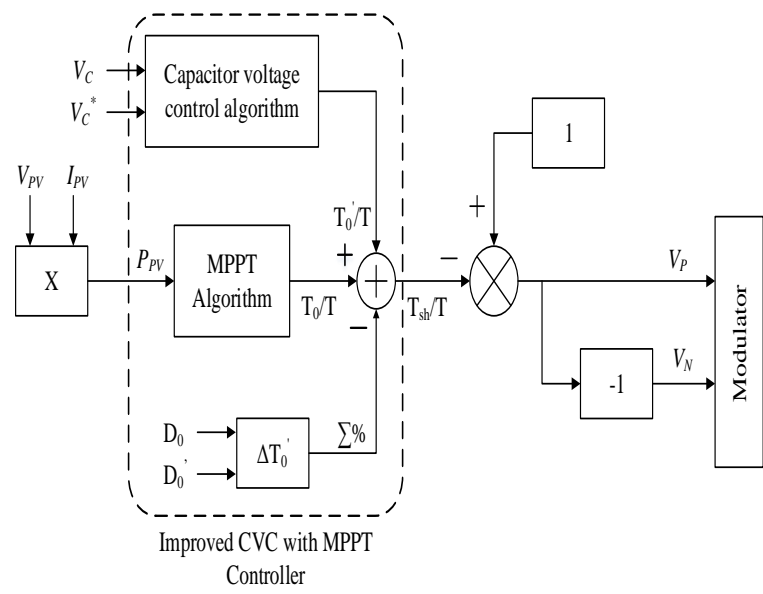

(b)

Figure 2. Z-source Inverter PV Power Conditioning System Control Block Diagram (a) Existing CVC Controller (b) Proposed CVC Controller

This paper is organized as follows: Proposed improved CVC algorithm based MPPT in Section 2. The whole system configuration is discussed in Section 3. Section 4 comprised result of simulation and discussion, followed by conclusion part is made in Section 5.

\section{PROPOSED CAPACITOR VOLTAGE CONTROL (i-CVC) BASED MPPT}

In this section, the development of the proposed controller will be discussed. For a solar power generation system, the MPPT and a stable output voltage are two main objectives of the system in order to achieve high efficiency output. Therefore, two control variables are involved in ZSI which is the shootthrough duty ratio and the modulation index as sugested from [13] that need to be considered. Therefore, iCVC control scheme is introduced in order to achieve both, MPPT and voltage control at Z-network as well by introducing the limiter boundary.

\subsection{Control Strategy Development}

The shoot-through period $\left(\mathrm{T}_{0}\right)$ is generated by traditional Perturb and Observe $(\mathrm{P} \& \mathrm{O})$ based on MPPT technique in order to extract maximum power point voltage from PV module [14], [15]. This $\mathrm{T}_{0}$ is unable to boost the capacitor voltage of Z-network further than the desired level due to the uncontrolled charging and discharging of Z-network impedances. Therefore, a capacitor voltage control of the impedance network is essential in order to control the capacitor voltage beyond the maximum power point voltage. It needs to be calculated using the shoot-through period $\left(\mathrm{T}_{0}\right)$ that requires to boost the capacitor voltage to the MPP voltage and combines with the additional shoot-through period $\left(\mathrm{T}_{0}\right)$ to control the capacitor voltage beyond the MPP voltage.

Unfortunately, the additional shoot-through period $\left(\mathrm{T}_{0}{ }^{\prime}\right)$ has some drawbacks as it boosts the capacitor voltage to a greater extent. Figure 3 shows the generation of the proposed controller with simple boost control method with two conditions of boundary of $\Delta \mathrm{T}_{0}$ ' while Fig.4 indicates the control algorithm for $\mathrm{P} \& \mathrm{O}$ based MPPT with embended i-CVC mechanism. It illustrates that, two references straight lines $\left(\mathrm{V}_{p}{ }^{*}\right.$ and $\mathrm{V}_{n}^{*}$ ) are continuously regulated to maintain $\mathrm{Z}$-source capacitor voltage.

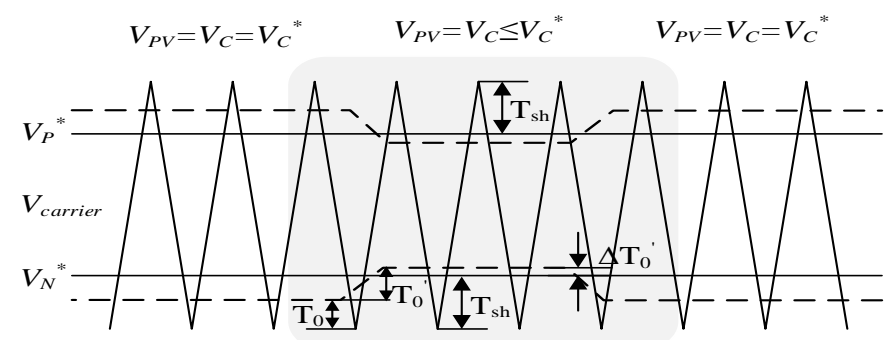

Figure 3. Shoot through generation by improved CVC control strategy 
The new shoot-through period $\left(\mathrm{T}_{\mathrm{sh}}\right)$ of MPPT control has been synchronized with improved CVC algorithm and can be defined as followed:

$$
\begin{aligned}
& T_{s h}=T_{0} \pm T_{0}{ }^{\prime} \mp \sum \% \Delta T_{0}^{\prime} \\
& D_{s h}=\frac{T_{s h}}{T}=\frac{T_{0}}{T} \pm \frac{T_{0}{ }^{\prime}}{T} \mp \sum \% \Delta T_{0}^{\prime}
\end{aligned}
$$

where, $\mathrm{D}_{\text {sh }}$ can be referred as the total shoot-through duty ratio and is equal to $\mathrm{T}_{\mathrm{sh}} / \mathrm{T}$. ( $\left.\mathrm{T}_{0}\right)$ is used to track $V_{P V}{ }^{*}$ by add or subtract the $\Delta \mathrm{T}_{0}$ for various climate condition at the PV input, while $\left(\mathrm{T}_{0}{ }^{\prime}\right)$ is used to control Zsource capacitor voltage according to reference capacitor voltage, $V_{C}{ }^{*}$. At the meantime, the additional $\mp \sum \%$ $\Delta \mathrm{T}_{0}$ ' will try to reduce the greater extent voltage occurs while boosting the capacitor voltage at Z-network by $\left(\mathrm{T}_{0}\right)$ to the reference value. As the result, the capacitor voltage will be controlled and able to maintain the DC link voltage as well. The range of the new shoot-through time period $\left(\mathrm{T}_{\mathrm{sh}}\right)$, can be written as suggested by the authors to:

$$
\frac{T_{s h}}{T} \mp \sum \% \Delta T_{0}^{\prime} \leq(1-M)
$$

where, $M$ is the modulation index. From equations (1) and (3) the following modified equation is obtained:

$$
\pm \frac{T_{0}^{\prime}}{T} \mp \sum \% \Delta T_{0}^{\prime} \leq 1-\left(M+\frac{T_{0}}{T}\right)
$$

Therefore, the maximum value of the additional shoot-through duty ratio for both cases can be written as followed:

$$
\begin{aligned}
& \left(\frac{T_{0}^{\prime}}{T} \mp \sum \% \Delta T_{0}^{\prime}\right)_{\max } \leq 1-\left(M+\frac{T_{0}}{T}\right)_{\text {when } \mathrm{V}_{\mathrm{C}} *>\mathrm{V}_{\mathrm{C}},} \\
& \left(\frac{T_{0}^{\prime}}{T} \mp \sum \% \Delta T_{0}^{\prime}\right)_{\max } \leq-\left(1-\left(M+\frac{T_{0}}{T}\right)\right)_{\text {when } \mathrm{V}_{\mathrm{C}} *<\mathrm{V}_{\mathrm{C}} .}
\end{aligned}
$$

Moreover, the modulation index $(\mathrm{M})$ and the MPPT shoot-through ratio $\left(\mathrm{D}_{0}\right)$ is used to limit the range of the additional shoot-through duty ratio $\left(\mathrm{D}_{0}{ }^{\prime}\right)$ combines with $\mp \sum \% \Delta \mathrm{T}_{0}$, and hence achieve the Zsource capacitor voltage control. Two constant references are employed to realize the new shoot-through period where now be equal to:

$$
\begin{aligned}
& V_{P}^{*}=\left[1-\left(\frac{T_{s h}}{T} \mp \sum \% \Delta T_{0}^{\prime}\right)\right]=\left[1-\left(D_{s h} \mp \sum \% \Delta T_{0}^{\prime}\right)\right] \\
& V_{N}^{*}=-\left[1-\left(\frac{T_{s h}}{T} \mp \sum \% \Delta T_{0}^{\prime}\right)\right]=-V_{P}^{*} .
\end{aligned}
$$

These two equations are compared with high-frequency carrier signal in order to generate the shootthrough pulse. Then, the DC link voltage or the capacitor voltage can be improved until it reaches the MPP voltage of the PV module $\left(V_{P V}{ }^{*}\right)$ and thus, able extract a maximum power from PV module. At the menatime, the average DC link voltage of the inverter can be expressed as:

$$
\bar{v}_{d c}=V_{C}=\frac{1-\left(D_{s h} \mp \sum \% \Delta T_{0}^{\prime}\right)}{1-2\left(D_{s h} \mp \sum \% \Delta T_{0}^{\prime}\right)} V_{P V}^{*} .
$$

On the AC side, the output peak voltage from the inverter can be defined as: 


$$
\hat{v}_{a c}=M\left[\frac{1-\left(D_{s h} \mp \sum \% \Delta T_{0}^{\prime}\right)}{1-2\left(D_{s h} \mp \sum \% \Delta T_{0}^{\prime}\right)}\right] \frac{V_{P V}^{*}}{2}=M \frac{\bar{v}_{d c}}{2} .
$$

The modulation index can be controlled from zero to $\mathrm{V}_{p}{ }^{*}$. In the meantime, the shoot-through states can be applied to all of the legs simultaneously whenever the triangular carrier signal is higher than the $\mathrm{V}_{p}{ }^{*}$ or lower than the $\mathrm{V}_{n}{ }^{*}$. Figure 4 shows $\mathrm{P} \& \mathrm{O}$ based MPPT algorithm with improved CVC algorithm.

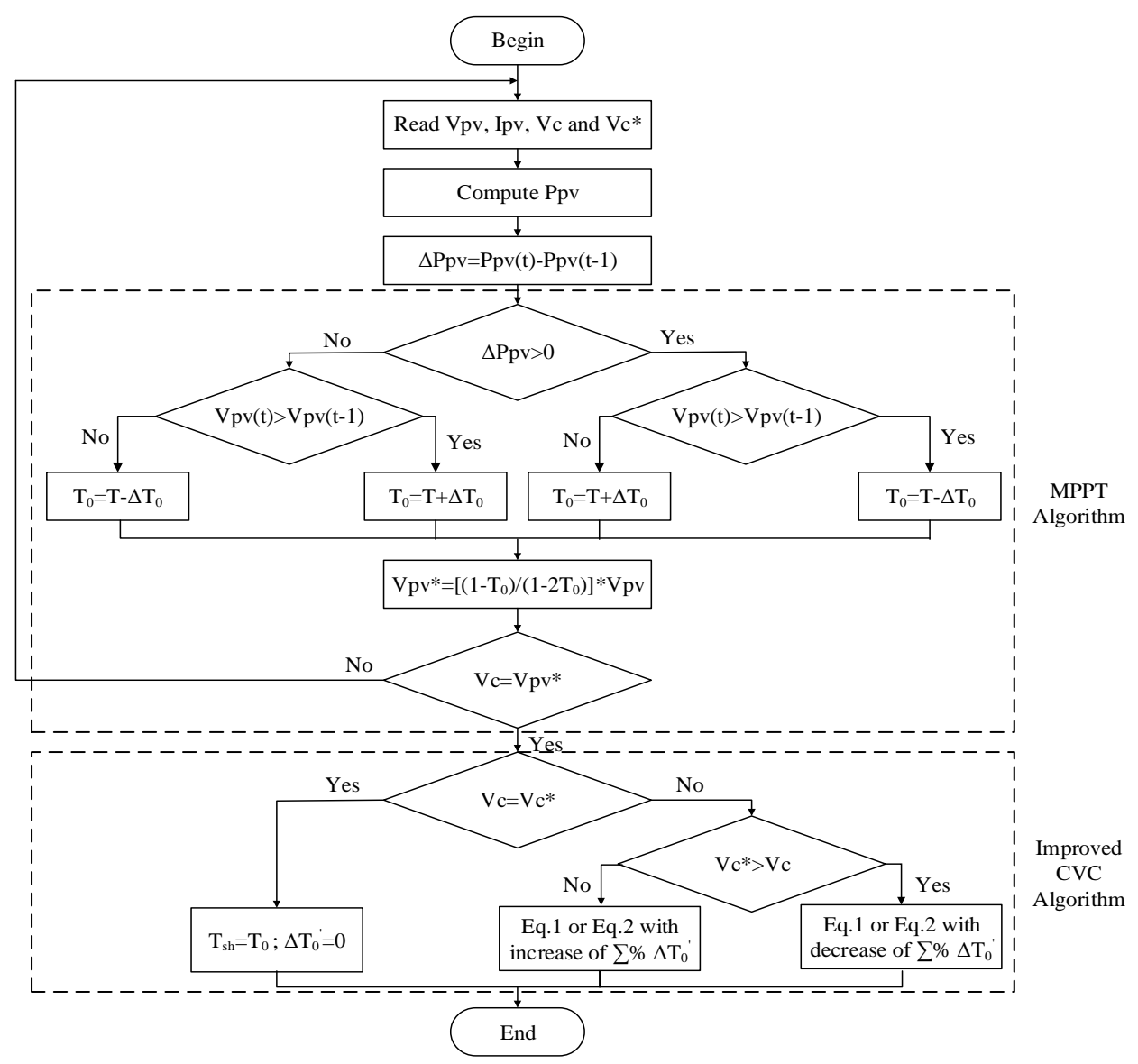

Figure 4. P\&O Based MPPT Algorithm with Improved CVC Algorithm

\subsection{Computation of $\mp \sum \% \Delta \mathrm{T} 0$ ' in i-CVC Algorithm}

In this improved control algorithm, the minimum shoot-through period is required to maintain the Zsource capacitor voltage while the PV voltage at MPP is generated by MPPT algorithm. The general capacitor voltage control (CVC) algorithm is to provide an additional boost in the capacitor voltage while at the same time to track the reference value.

There are three cases in order the capacitor voltage to track the maximum power of PV array where, at first, when the reference capacitor voltage, $V_{C}{ }^{*}$ is equal to the voltage of PV at MPP, $V_{P V}{ }^{*}$. Therefore, only the shoot-through state $\left(\mathrm{T}_{0}\right)$ is varied to regulate the capacitor voltage while the net shoot-through remains at $\mathrm{T}_{0}$. In this case, the shoot-through duty cycle will be set to $\mathrm{D}_{0=} 0.083$. For the second case, as for example, if $1000 \mathrm{~W} / \mathrm{m}^{2}$ and $25^{\circ} \mathrm{C}$ irradiant, the voltage delivered by PV panel $V_{P V}$ is $17 \mathrm{~V}$ and the maximum power point of the PV panel under this condition is $19 \mathrm{~V}$. Now, the shoot-through period generates an extra $2 \mathrm{~V}$ higher at the Z-source capacitor. The required shoot-through period can be derived from Equation 11 as:

$$
v_{d c}=V_{C}=\frac{1-D_{0}}{1-2 D_{0}} V_{P V}=V_{P V}^{*}
$$


This shoot-through period is varied during various irradiant conditions by adding or subtracting the $\Delta \mathrm{T}_{0}$ and the capacitor voltage boost factor, $B_{c}$ can be simplified as followed

$$
B_{C}=\frac{V_{P V}^{*}}{V_{P V}}=\frac{V_{C}^{*}}{V_{P V}} .
$$

From Equation 12, the $B_{c}$ is calculated to about 1.118 and thus, the shoot-through duty ratio can simply calculate as:

$$
D_{0}=\frac{T_{0}}{T}=\frac{B_{C}-1}{2 B_{C}-1},
$$

and give the $\mathrm{D}_{0}$ equal to 0.095 .

For the third case, it is when the capacitor voltage is more than the desired value and beyond the $V_{P V}{ }^{*}$ as required in DC link voltage. For example, at $1000 \mathrm{~W} / \mathrm{m}^{2}$ and $25^{\circ} \mathrm{C}$, the voltage is delivered by $17 \mathrm{~V}$ in PV panel and the maximum power point of the PV panel under is targeted value to be $22 \mathrm{~V}$. The $22 \mathrm{~V}$ will be the voltage to maintain the capacitor across the Z-source capacitor. As been detailed in the previous case, the shoot-through time period is to boost the capacitor voltage to this new MPP voltage of PV panel is 0.115 . Although, if the additional shoot-through period $\left(\mathrm{T}_{0}{ }^{\prime}\right)$ is required for boosting capacitor voltage more than to $22 \mathrm{~V}$, it can be calculated using Equations 12 and 13. However, the extra shoot-through duty ratio, $\mathrm{D}_{0}$ ' produces around 0.185 for this case.

In order to increase the efficiency of PV output from the MPPT controller, the suggested improved capacitor voltage control (i-CVC) algorithm must able to handle any values of capacitor voltage at Z-network is employed and suggested. This improved algorithm is able to operate well especially during when, the reference capacitor voltage is lower than the Z-source capacitor voltage. By adding an extra ratio which about $\mp \sum \%$ of the changes between shoot-through duty cycle for $\mathrm{D}_{0}$ upon the extra shoot-through duty cycle and $\mathrm{D}_{0}$ at the CVC algorithm. It will prove the effectiveness of this algorithm. This percentage has been proved through the calculation in next explanation paragraph.

To verify the application of $\mp \sum \% \Delta \mathrm{T}_{0}$, let the reference capacitor voltage, $V_{C}$ ' is equal to the voltage of PV at MPP, $V_{P V}{ }^{*}$ and the shoot-through duty remains unchanged which is $\mathrm{D}_{0=} 0.083$ as stated earlier in the first case. Then, take the reference capacitor voltage, $V_{C}$ more than to the voltage of PV at MPP, $V_{P V}{ }^{*}$. As known earlier, the maximum reference voltage is set to $22 \mathrm{~V}$. Thus, the additional duty cycle requires to boost is $\mathrm{D}_{0}{ }^{\prime}=0.185$ and the total shoot-through duty ratio $\left(\mathrm{D}_{\mathrm{sh}}\right)$ will regulate to a constant $\mathrm{DC}$ input value. However, during the changes between second case and the third case, $D_{\text {sh }}$ has an extra increasing which is more than the desired level. Since that, an additional $\mp \sum \%$ will be applied to reduce the increment in delta changes of shoot-through over additional shoot-through duty, $\Delta \mathrm{T}_{0}$ ' where $\Delta \mathrm{T}_{0}$ ' given as,

$$
\Delta T_{0}^{\prime}=\frac{D_{0}}{D_{0}^{\prime}} .
$$

By recalculating the required total shoot-through in $\mathrm{i}-\mathrm{CVC}$, it is about $10 \%$ to $14 \%$ of $\Delta \mathrm{T}_{0}$ ' needs to be reduced in order to have a constant capacitor voltage at impedance Z-network. Considering the initial step size, $\Delta \mathrm{T}_{0=} 0.02$, another $2 \%$ off from the required percentage and this makes it becomes $12 \%$. Therefore, the new shoot-through period to be inserted into all the switching waveforms can be derived as in Equation 1 with $\mp 12 \%$ of $\Delta \mathrm{T}_{0}$. The improvement of this algorithm towards capacitor voltage control not only reliable for ZSI implementation, it also will increase the effectiveness of the whole PV system shown in Section 4.

\section{SYSTEM CONFIGURATION}

In this section, the whole system configuration of the proposed control algorithm for ZSI-based PV system will be provided. The PV module is the input to the system while the Z-source inverter is the power converter topology that equippes with an improved MPPT-CVC controller. This controller is used to obtain the voltage respond by the PV module in order to achieve maximum power point. The basic Perturb and Observe (P\&O) algorithm for a standalone system [16] is used in ZSI with a combination of Z-source improved capacitor voltage control. At the end, the CVC is able to boost the capacitor voltage at impedance network to be twice is possible or more than the desired level at DC link terminal. 


\subsection{Single-stage PV Conversion System for Z-source Inverter}

As known, the PV is a non-linear current-voltage and power-voltage characteristic is continuously varied with temperature and irradiance. The PV model has been developed using the basic circuit equation of the solar cells. Here, the MSX-60 poly-crystalline silicon PV module parameters are used as input into the PV system equations which described the current output of the PV solar. Ideally, continuous varying maximum power point of the solar PV module is being tracked using MPPT control technique.

A Z-source inverter plays an important part in order to increase dc voltage output and as the DC-AC conversion in a single stage that is not available in traditional PV power conditioning system. The ZSI is composed of split-inductors $L_{1} \& L_{2}$ and capacitors $C_{1} \& C_{2}$ which are been connected in cross-shape [17]. The inductors are used to regulate the current ripples and reduces harmonics while the two capacitors are used to regulate voltage ripples and produce pure dc at the inverter input. The ZSI has three operation modes shown in Fig.5: active mode, shoot-through mode, and traditional zero-state mode [18]. During active and zero-state mode, the ZSI operates under the traditional pulse width modulation (PWM) pattern. In the shootthrough mode, the inverter bridge is seen as a short circuit from the DC-link point of view [19].

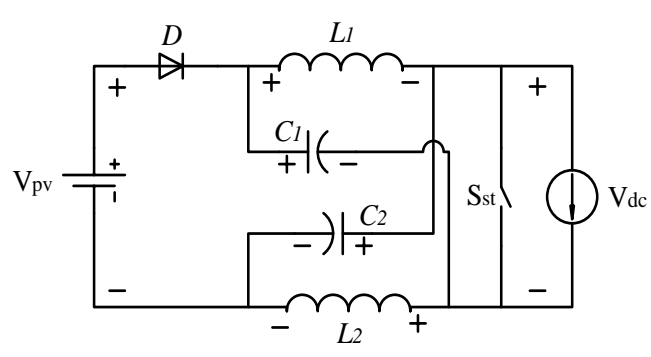

(a)

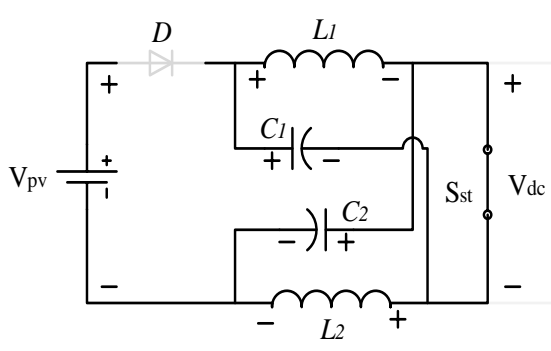

(b)

Figure 5. Operating Modes of ZSI. (a) During Non-shoot-through (b) During Shoot-through

Then the DC capacitor voltage can be boosted as,

$$
v_{d c}=V_{C}=\frac{1-D_{s h}}{1-2 D_{s h}} V_{P V}=V_{P V}^{*} .
$$

$\mathrm{D}_{\mathrm{sh}}$ is the net shoot-through duty ratio obtained after boosting the capacitor voltage to the desired level.

\subsection{Selective of Z-network Parameter}

The most challenging in designing the ZSI circuitry is the estimation of values for reactive components in impedance network. During the shoot-through time, the Z-source inductor current will discharge the capacitor voltage [20], therefore, the ripple amplitude of the capacitor voltage can be expressed as,

$$
\Delta V_{C}=\frac{D_{0} I_{L}}{f_{0} C}
$$

and by rearranged equation 16 , it gives

$$
C=\frac{D_{0} I_{L}}{f_{0} \Delta V_{C}}
$$

The maximum current through the inductor occurs when the maximum shoot-through happens. This will cause a high current ripple to the $\mathrm{Z}$-source inductor. In this design, $60 \%$ of peak-to-peak current ripple through the Z-network inductor during maximum power operation is been chosen. For the designing of $\mathrm{Z}$ network inductor value, a constant capacitor voltage, $V_{C}$ and the ripple current need to be considered. The ripple amplitude of the inductor current is given as,

$$
\Delta I_{L}=\frac{D_{0} V_{C}}{f_{0} L} .
$$


From Equation 18, the inductance can be calculated as

$$
L=\frac{D_{0} V_{C}}{f_{0} \Delta I_{L}} .
$$

Therefore, all the parameters are being obtained simultaneously. The Z-network inductance, $L_{1}=L_{2}=L=870 \mu \mathrm{H}$ while the for the capacitance, $C_{l}=C_{2}=C=2000 \mu \mathrm{F}$ and capacitive value of PV output voltage, $C_{P V}=1000 \mu \mathrm{F}$. Here, the renonant circuit required a resonant capacitance, $C_{r}=1000 \mu \mathrm{F}$ with $10 \Omega$ resistive load. For $\bar{\mp} \sum \%$ of delta shoot-through, $\Delta \mathrm{T}_{0}{ }^{\prime}$ required in this simulation test and applicable in this ZSI-PV system is about $12 \%$.

\subsection{Controller Design Parameter for Voltage Control}

As for the bridge inverter control, taking the output voltage of single-phase inverter as a controlled voltage source, $v_{a c}$ and been combined with the LC filter design to obtain the equivalent circuit as shown in Figure 6.

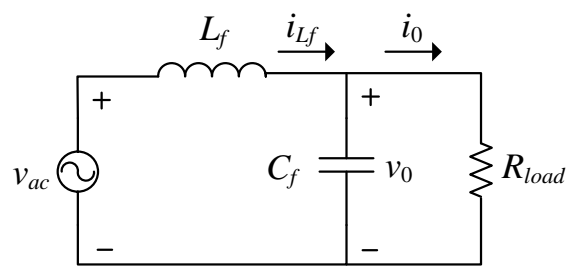

Figure 6. Equivalent circuit of bridge inverter with LC filter

Assume an ideal AC load which is a resistive load R, then the transfer function of the circuit will be expressed as,

$$
G_{f}(s)=\frac{1}{L_{f} C_{f} s^{2}+\frac{L_{f}}{R} s+1},
$$

which is a typical second-order system. However, from the bode plot in Fig.7(a), shows the design controlled plant of AC inverter output voltage loop is unstable. Therefore, the design of the voltage control loop involves the design of PI controller has been used.

For the voltage control loop, the PI control parameters are designed to get zero-steady state error at the load voltage and $50 \mathrm{~Hz}$ without affecting the transient response. There are two parameters consist in this section which is the Proportional (P) and the Integral (I). Before the gains of the PI can be selected, the compensating transfer function network by combining $\mathrm{G}_{\mathrm{f}}(\mathrm{s})$ in equation 20 with the ideal compensator of

$$
G_{P I}(s)=K_{P}+\frac{K_{i}}{s}
$$

where $\mathrm{Kp}$ is proportional gain and $\mathrm{Ki}$ is the integral gain. Then, the voltage closed-loop control system and its closed-loop transfer function is respectively given as

$$
G(s)=G_{P I}(s) G_{f}(s) \text {. }
$$

Figure 7 shows the bode plot of voltage control loop transfer function, G(s) with compensator and without the compensator been additing to the plant. By adjusting the gain of the PI regulator, the suitable values for proportional gain, $\mathrm{Kp}=0.575$ and integral gain, $\mathrm{Ki}=0.001$ are obtained from Fig. $7(\mathrm{~b})$. It can be seen that, the phase margin of the Gf(s) is increased to $90^{\circ}$ after the compensation, which indicates a stable feature of the closed-loop system. 


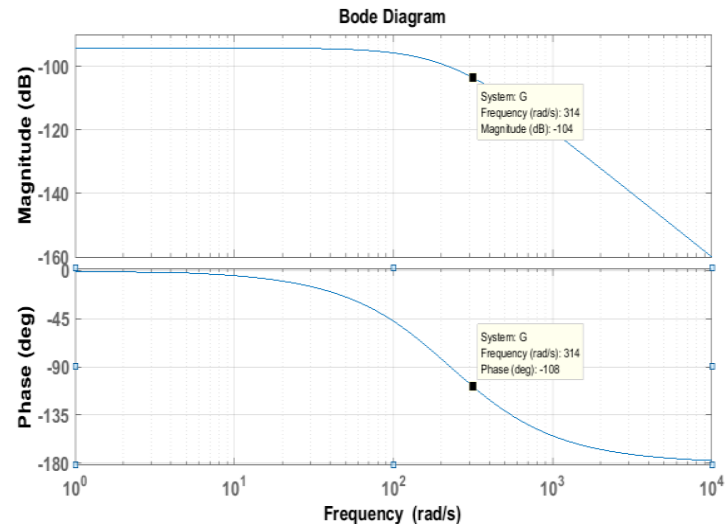

(a)

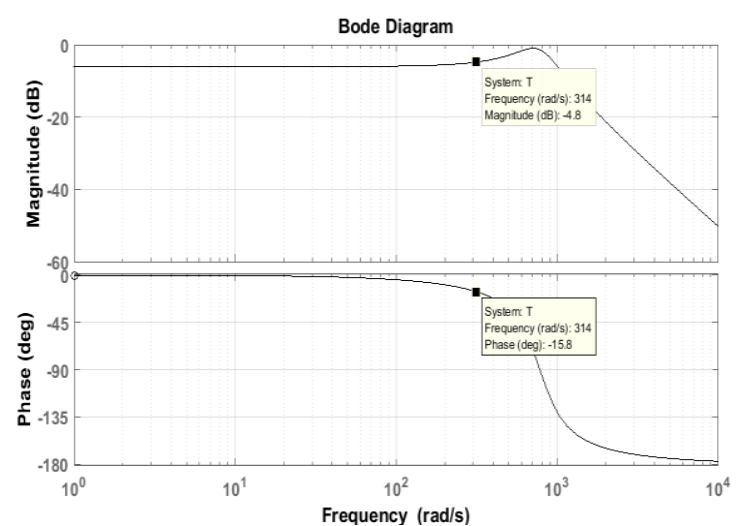

(b)

Figure 7. Bode Plots of the Voltage Control Loop (a) Controlled Plant Before Compensation (b) Controlled Plant After Compensation

\subsection{Pulse Width Modulation (PWM) Control Generation based on i-CVC}

The shoot-through state can be applied in conventional PWM in order to make the resonant switch is ON simultaneously during two switches in the same legs. A modified PWM strategy is implemented, which will ensure a single power device switching per state transition. One of the methods in order to generate PWM signal is by using sinusoidal PWM [21], [22] combining with the i-CVC as shown in Figure 8.

In addition, a gate signal is necessary for the complement of a shoot-through signal to improve the switching pattern in ZSI. A quasi-resonant Z-source inverter is formed by adding a quasi-resonant network with only one auxiliary switch connected in parallel between Z-network and the inverter. All switches in the inverter are turned on and off under a zero-voltage switching condition. This topology for ZSI had almost a $10 \%$ overall efficiency increase compared with the hard switching. Therefore, this high-performance structure can eliminate the possibility of the DC-link voltage drop with an additional advantage of being stable for all ranges of the modulation index during shoot through state.

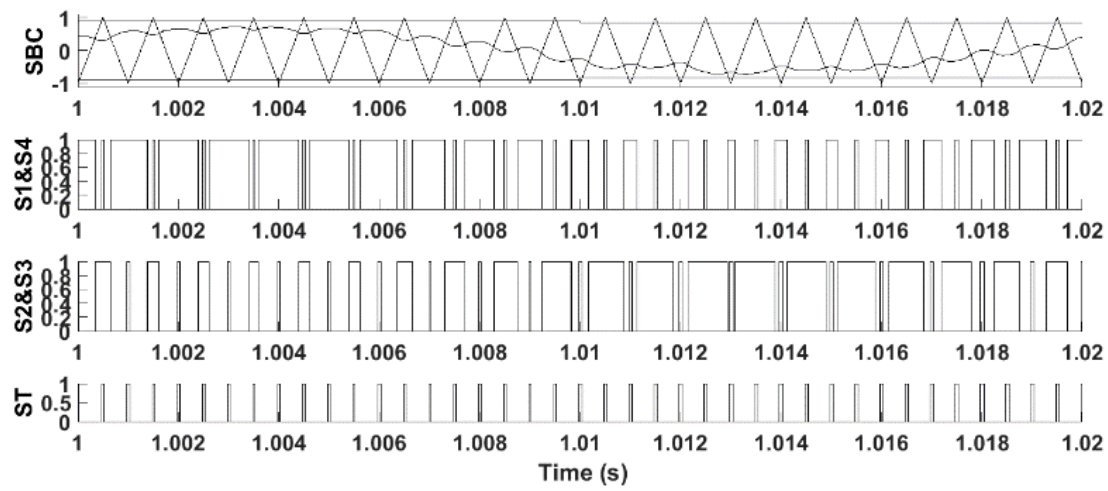

Figure 8. The modified PWM and switching state of ZSI

\section{RESULT AND DISCUSSION}

In this part, the proposed algorithm has been validated through simulation tests using MATLAB/Simulink tools. The simulation model shows exactly how by implementing of $\Delta \mathrm{T}_{\mathrm{o}}$ in duty cycle in additional shoot through will affect the PV system efficiency in term of voltage and power output. There are two different cases or condition of irradiation have been tested in order to see the effectiveness of the algorithm. Firstly, by considering a constantly changes in irradiation and for the second case is when the irradiation is suddenly dropped at a specific time. The simulation time duration of simulations has been set up to $2 \mathrm{~s}$ whereas some figures have been zoomed in order to have a clear visualization of signals during the changes of irradiation and the DC and inverter outputs performance. In this simulation, the PV module is simulated for a different irradiance but with a constant temperature of $25^{\circ} \mathrm{C}$. 


\subsection{Case I: Constantly Change in the Irradiation}

Initially, the PV module is simulated using a constant change of irradiations as designed in Figure 9(a) while Figure 9(b) shows the PV output has been maintained as suggested by authors. As can be seen in Figure 10(a), whenever the constant changes occur, the improved MPPT-CVC voltage of PV module is able to have a constant capacitor voltage for the Z-source. For example, at $0.4 \mathrm{~s}$ until $1.2 \mathrm{~s}$ the irradiance is increased constantly until it reaches to the maximum reference voltage, while the capacitor in Z-network, is able to maintain at $V_{C=22} \mathrm{~V}$ at $\mathrm{S}=1000 \mathrm{~W} / \mathrm{m}^{2}$. After that, the module's irradiation is given by slightly decreased to $900 \mathrm{~W} / \mathrm{m}^{2}$ from 1.2 to $1.8 \mathrm{~s}$ in the simulation. It shows that the improved algorithm on i-CVC seems to have ability to control the voltage at impedance network circuitry to be constant as well as the voltage across inverter's DC link terminal voltage in Figure 10(b).

Based on the result, it indicates that the capacitor voltage control with an auxiliary switch is able reduced relatively high fluctuations in order to track maximum power point. This improved controller with additional switch has a better performance as it able to suppres the capacitor voltage ripple too. Due to the constant capacitor voltage at any conditions of solar irradiance, this proposed i-CVC algorithm with the help of additional switch to the system is preferred.

At the meantime, Figure 11 shows the inverter output voltage is regulated to almost $20 \mathrm{~V}$ as adequate to provide $20 \mathrm{~V}$ output and output current of $2 \mathrm{~A}$ respectively with a resistive load of $10 \mathrm{ohms}$. It indicates that the obtained the gains for PI controller from the bode plot technique manage to ensure the filter output voltage to follow the reference target value.

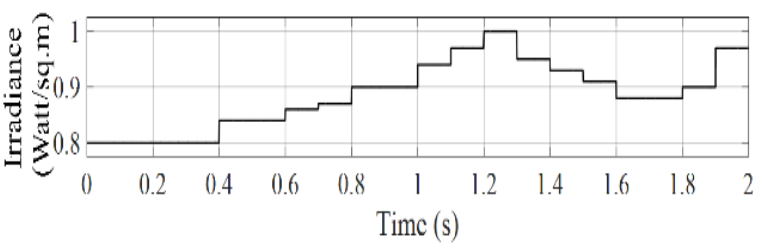

(a)

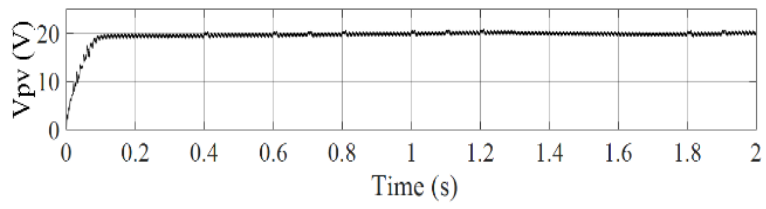

(b)

Figure 9. Input of ZSI for Case 1 (a) Constantly Changes Irradiation at PV (b) PV Output Voltage

During Constantly Changing Irradiation

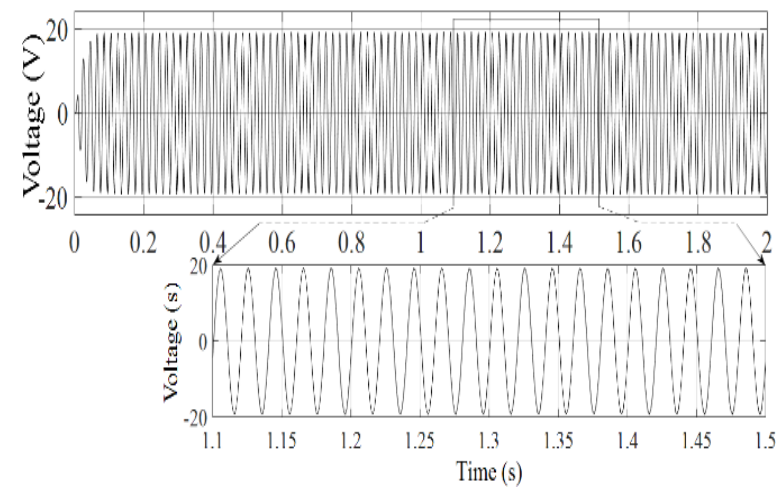

(a)

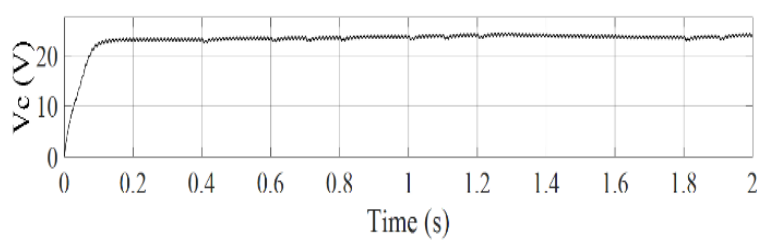

(a)

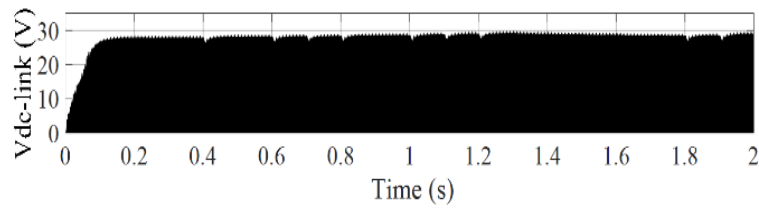

(b)

Figure 10. Output of ZSI for Case 1 (a) Capacitor Voltage and, (b) DC-link Voltage at Z-network During Constantly Changing Irradiation

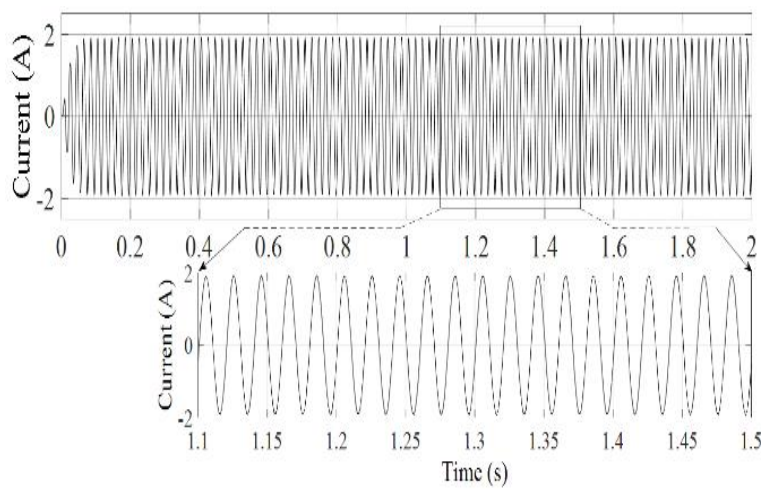

(b)

Figure 11. Output Voltage Filter During Constantly Changing Irradiation (a) AC Output Voltage (b) AC Output Current 


\subsection{Case II: Sudden Changes in the Irradiation}

Similar to the case I, but for this simulation, a sudden change of irradiance as shown in Figure 12(a) while Figure 12(b) the output PV has been applied using the i-CVC in order to verify the efficiency of the proposed algorithm. Figure 13 shows the performance of capacitor voltage control in order to maintain the Znetwork capacitor voltage and the DC link voltage at the same time. The same response for the case I is obtained when the irradiation is changed slowly at time $0.5 \mathrm{~s}$. During 1 to $2 \mathrm{~s}$ of simulation time, the module is working at $800 \mathrm{~W} / \mathrm{m}^{2}$, then a suddenly drop and this cause a small decrease in the capacitor voltage shown in Figure 13(a).

From the aforementioned, the proposed i-CVC algorithm verifies that the additional delta changes about $\mp 12 \%$ in the extra shoot-through duty ratio able to maintain the capacitor voltage at Z-network. Clearly, it proves that, when there is changed of irradiation, the PV module output voltage is still working at the MPP voltage, and the shoot through duty ratio is automatically regulated to keep the peak DC-link voltage to be consistent as in Fig.13(b). It produces an additional boost in capacitor voltage to track the given reference value. Same output performances for the voltage and current after the inverter as in the case 1 . The PI control strategy is able to track the given reference voltage even after there is rapidly changing of irradiation.

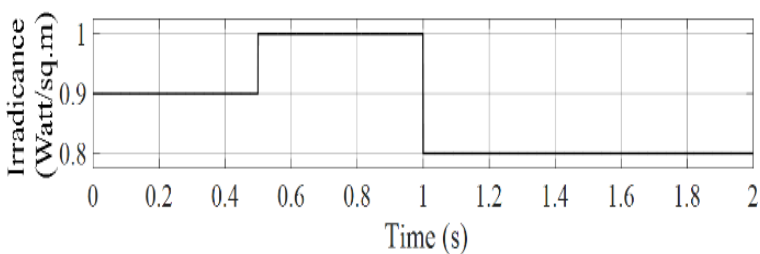

(a)

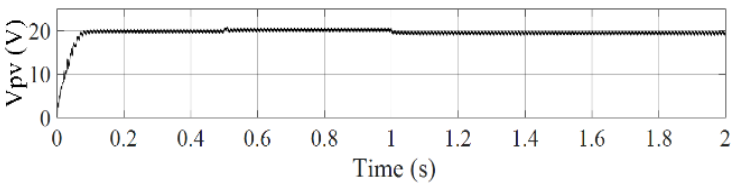

(b)

Figure 12. Input of ZSI for Case 2 (a) Suddenly Changes Irradiation at PV (b) PV Output Voltage During Suddenly Changing Irradiation

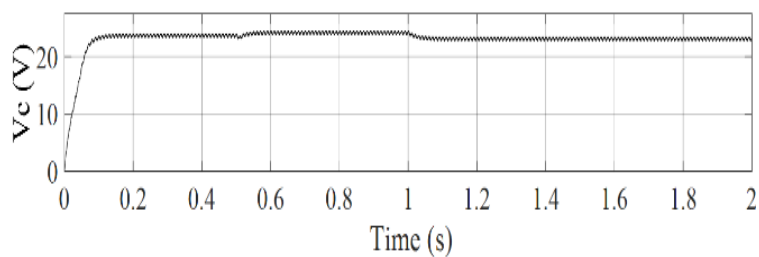

(a)

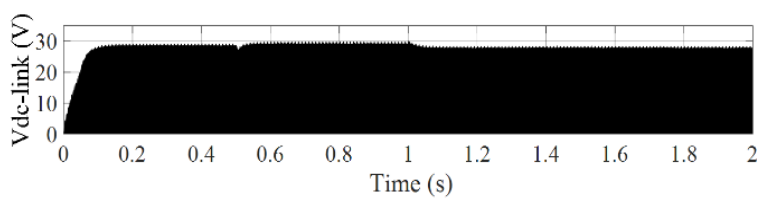

(b)

Figure 13. Output of ZSI for Case 2 (a) Capacitor Voltage and, (b) DC-link Voltage at Z-network During Suddenly Changing Irradiation

\subsection{Comparison Between Existing CVC with Improved CVC}

Figure 14 shows the comparison performance of capacitor voltage by using existing CVC and iCVC. From the results, it can be seen that the proposed controlled capacitor voltage has the ability to track the voltage at MPP faster compared to the existing CVC while having a constant output at ZSI. The capacitor voltage obtained almost $24.5 \mathrm{~V}$ which is nearly the given reference capacitor voltage, $V_{C}{ }^{*}=22 \mathrm{~V}$.

Furthermore, the improved $\mathrm{CVC}$ has not only increase the tracking accuracy, but it also has a high tracking speed which is $0.04 \mathrm{~s}$ faster than the existing CVC. Even so, the PI voltage control also has achieved a good performance for both controllers as shown in Figure 15. The output voltage after the inverter gives almost the same but with some improvement in improved CVC. The total harmonic distortion of the ouput voltage, $\mathrm{THD}_{v}$ by using the improved controller also has been reduced from $1.13 \%$ to $0.95 \%$ as shown in Figure 16 (a) and (b).

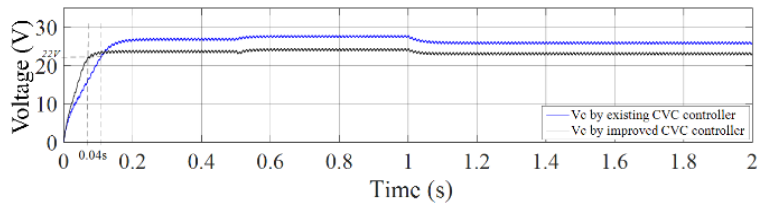

Figure 14. Capacitor voltage by using existing CVC and improved CVC

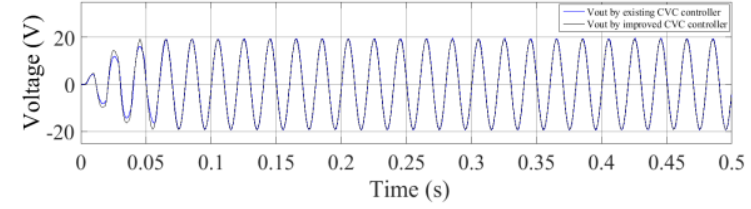

Figure 15. Inverter output voltage by using existing CVC and improved CVC 


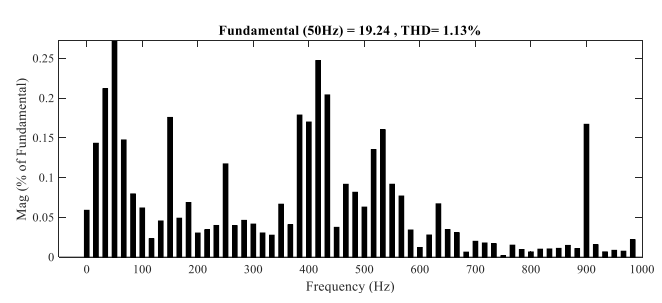

(a)

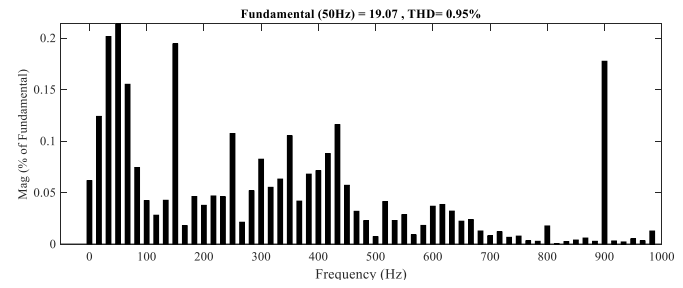

(b)

Figure 16. $\mathrm{THD}_{v}$ of Output Voltage by Using (a) Existing CVC Controller, and (b) Improved CVC Controller

\section{CONCLUSION}

As a conclusion, this paper has introduced an i-CVC algorithm by combining with a conventional MPPT algorithm based on the switching pattern of Z-source inverter with improved shoot through effect. This controller realizes both conditions during varying and sudden changes of irradiation as it can regulate the capacitor voltage at impedance source to be maintained continuously. The effectiveness of the proposed controller has been verified using simulation tests with a well-designed of the control voltage parameter. From the results, the i-CVC with $\mathrm{P} \& \mathrm{O}$ based MPPT method can produce higher tracking accuracy as well as having a fast tracking speed compared to the existing capacitor voltage controller.

\section{ACKNOWLEDGEMENTS}

The authors gratefully acknowledge the financial supports from the Centre for Graduate Studies, Universiti Tun Hussein Onn Malaysia (UTHM) and GPPS (U797) grant. These supports enabled the authors to undertake this research activity. The authors would also like to thank the Advanced Control on Power Converters Group at Makmal Kuasa Elektronik, FKEE, UTHM for providing the facilities.

\section{REFERENCES}

[1] L. H. Pratomo, F. D. Wijaya, and E. Firmansyah, "Capacitor Bank Voltage Equilibrium for MPPT in Single-Phase Single-Stage Five-Level Inverter for PV-Grid Application,” TELKOMNIKA Indones. J. Electr. Eng., vol. 14, no. 1, pp. 62-71, 2015.

[2] Z. Rasin and M. F. Rahman, "Design and simulation of quasi-Z source grid-connected PV inverter with battery storage," PECon 2012 - 2012 IEEE Int. Conf. Power Energy, vol. 8, no. December, pp. 303-308, 2012.

[3] S. Thangaprakash, "Unified MPPT Control Strategy for Z-Source Inverter Based Photovoltaic Power Conversion Systems," J. Power Electron., vol. 12, no. 1, pp. 172-180, 2012.

[4] A. Zakerian and D. Nazarpour, "New hybrid structure based on improved switched inductor Z-source and parallel inverters for renewable energy systems," Int. J. Power Electron. Drive Syst., vol. 6, no. 3, pp. 636-647, 2015.

[5] E. Babaei and E. S. Asl, "A new topology for Z-source half-bridge inverter with low voltage stress on capacitors," Electr. Power Syst. Res., vol. 140, pp. 722-734, 2016.

[6] R. Adle, M. Renge, S. Muley, and P. Shobhane, "Photovoltaic Based Z-Source Inverter Fed Induction Drive with Improved Shoot-Through Technique,” Energy Procedia, vol. 117, pp. 329-335, 2017.

[7] J. P. Ram, T. S. Babu, and N. Rajasekar, "A comprehensive review on solar PV maximum power point tracking techniques," Renew. Sustain. Energy Rev., vol. 67, pp. 826-847, 2017.

[8] M. Balamurugan, S. Kumar, and S. Sukchai, "Application of soft computing methods for grid connected PV system : A technological and status review," vol. 75, pp. 1493-1508, 2017.

[9] A. A. Hakeem, A. Elserougi, A. El Zawawi, and S. Ahmed, "A Modified Capacitor Voltage Control Algorithm for Suppressing the Effect of Measurement Noise on Grid-Connected Z- Source Inverters Controllers," Ind. Electron. Soc. IECON, 39th Annu. Conf. IEEE, pp. 204-209, 2013.

[10] A. Ho and T. Chun, "Modified Capacitor-Assisted Z-Source Inverter Topology with Enhanced Boost Ability," J. Power Electron., vol. 17, no. 5, pp. 1195-1202, 2017.

[11] J. H. Park, H. G. Kim, E. C. Nho, and T. W. Chun, "Capacitor voltage control for MPPT range expansion and efficiency improvement of grid-connected Quasi Z-Source Inverter,” 2010 Int. Power Electron. Conf. - ECCE Asia -, IPEC 2010, pp. 927-931, 2010.

[12] S. K. Kollimalla, S. Member, M. K. Mishra, and S. Member, "Variable Perturbation Size Adaptive P \& O MPPT Algorithm for Sudden Changes in Irradiance," IEEE Trans. Sustain. Energy, vol. 5, no. 3, pp. 718-728, 2014.

[13] Y. S. Chiu, C. L. Liu, Y. H. Liu, and K. Y. Lin, "Z-Source Inverter-based Standalone Photovoltaic Generation System with MPPT Capability,” Proc. 2014 Int. Conf. Intell. Green Build. Smart Grid, IGBSG 2014, no. 8, pp. 8$11,2014$.

[14] V. Aswini, B. M.Manjunath, and J. N. Reddy, "Unified MPPT Control Strategy for Z-Source Inverter," Int. J. Res. 
Appl. Sci. Eng. Technol., vol. 3, no. 8, pp. 234-242, 2015.

[15] A. Kumar and A. Bhattacharya, "Three Level Z-Source Inverter Based Photovoltaic Power Conversion Systems," Ind. Electron. Soc., pp. 1357-1362, 2015.

[16] W. K. Francis, P. S. B. S, and P. J. Mathew, "MATLAB / Simulink PV Module Modelof P \& O And DC Link CDC MPPT Algorithmswith Labview Real Time Monitoring And Control Over P \& O Technique," Int. J. Adv. Res. Electr. Electron. Instrum. Eng., vol. 3, no. 5, pp. 92-101, 2014.

[17] H. Omar Ellabban and Abu-Rub, "Z-Source Inverter;Topology Improvements Review," vol. 10, no. 1, pp. 6-24, 2016.

[18] B. Nayak, S. S. Dash, and S. Kumar, "Proposed method for shoot-through in three phase ZSI and comparison of different control techniques," Int. J. Power Electron. Drive Syst., vol. 5, no. 1, pp. 32-44, 2014.

[19] M. F. N. Tajuddin, B. Ismail, A. Azmi, S. M. Ayob, and Z. Salam, "Single Phase Z-Source Inverter with Differential Evolution (DE) based Maximum Power Point Tracker," TELKOMNIKA Indones. J. Electr. Eng., vol. 14, no. 1, pp. 80-89, 2015.

[20] V. Saravanan, M. Aravindan, V. Balaji, and M. Arumugam, "Experimental Verification of Single Phase Z Source Inverter for Photovoltaic Applications," Int. J. Power Electron. Drive Syst., vol. 9, no. 2, pp. 698-703, 2018.

[21] Suroso, A. N. Aziz, and T. Noguchi, "Five-level PWM Inverter with a Single DC Power Source for DC-AC Power Conversion," Int. J. Power Electron. Drive Syst., vol. 8, no. 3, pp. 1230-1237, 2017.

[22] V. R. Rajan, C. S. A. Sekhar, R. H. Kumar, and M. Sasikumar, "Comparative Evaluation of Generalized Multicell Impedance Source Inverter for Drives,” Int. J. Power Electron. Drive Syst., vol. 4, no. 1, pp. 61-69, 2014.

\section{BIOGRAPHY OF AUTHORS}
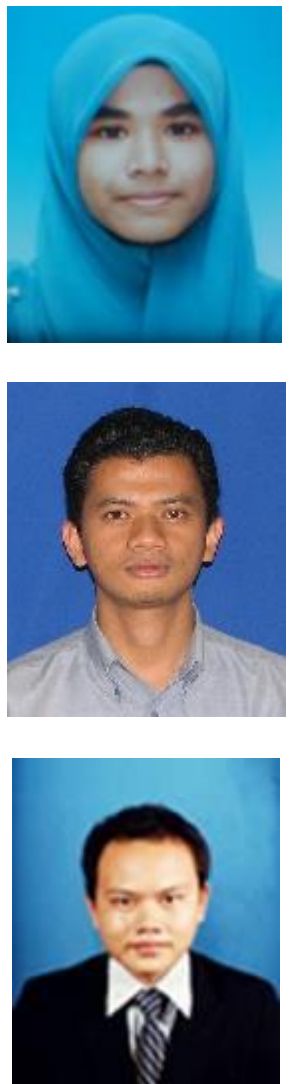

Noor Mazliza Badrul Sham received Diploma and B.Eng. (Hons.) degree in electrical engineering from Universiti Tun Hussein Onn Malaysia in 2014 and 2017, respectively. She is currently a Master student in Faculty of Eletrical and Electronic Engineering, Universiti Tun Hussein Onn Malaysia. Her current research includes power electronic and control strategy for renewable energy.

Shamsul Aizam Zulkifli received B.Eng. (2003) and M.Sc (2006) from Universiti Putra Malaysia and PhD. (2012) degree in Control System Engineering from Loughborough University, UK. He is currently a Senior Lecturer with the Department of Elelctrical Power Engineering, Faculty of Eletrical and Electronic Engineering, Universiti Tun Hussein Onn Malaysia. His research interests are in robust control system on power electronics application, parallel inverter application and smart grid topology for inverter-grid connection.

The author was born in 18 November 1991, in Sarawak, Malaysia. He got early education at Sekolah Kebangsaan St. Raymond Mujat, Serian, Sarawak in year 2002 and continued his studies in secondary level at Sekolah Menengah Kebangsaan Tebakang, Serian, Sarawak before he went to Sekolah Menengah Teknik Sejingkat, Kuching, Sarawak in year 2008. He pursued his study at Politeknik Kuching Sarawak, in Sarawak, Malaysia for diploma level. Before he further his study, he working as a technician in field of lighting installation and domestic wiring. He graduated with the B.Eng.(Hons) in Electrical Engineering in 2017 from University Tun Hussein Onn Malaysia, Johor. 